\title{
PEDAGOGICAL APPROACH FOR STRUCTURAL STABILITY WITH NUMERICAL IMPLEMENTATION
}

Yargo Pezzin Souza ${ }^{1}$, Walnório Graça Ferreira ${ }^{2}$

DOI: 10.37702/REE2236-0158.v40p173-180.2021

\begin{abstract}
This article aims to present a Stability Theory in a compact pedagogical way, where important concepts, analytical, and numerical procedures are included. The strong point of this article is the simplicity of the presentation of the nonlinear geometric analysis. Numerical computational procedures are presented for geometric nonlinear system analysis in order to facilitate understanding for those who intend to study the subject because it brings the basic concepts and the numerical implementations that can be used for the solution of more complex problems. Computational implementation details and analytical solutions are presented for two examples: single and multiple degree of freedom systems (SDOF and MDOF systems, respectively). The first one, the single degree of freedom scalar problem, is presented because it contains a limit load point, a dynamic jump, and the geometric imperfections influence, besides incorporating additional important concepts. The second one, a MDOF system, represented by a two degrees of freedom problem, is presented to introduce to matrix algebra.
\end{abstract}

Keywords: stability, nonlinear geometric analysis, Newton-Raphson procedure.

\section{INTRODUCTION}

The goal of structural engineering has been to provide economical structures without loss of safety or durability. The constant increase in the resistance of the materials has allowed the execution of structures increasingly light and slender. As the structural elements become moreslender, the structure becomes more susceptible to lateral deflections. In these cases, the displacements generated by load increments assume important geometric nonlinear behavior (FERREIRA, 2004). A nonlinear system can exhibit more than one equilibrium configuration, some stable and some unstable. Consequently, it is mandatory to perform a precise nonlinear stability analysis of the structure.

The analytical response with a rigorous nonlinear approach is only possible in extremely simple mechanical systems. In general, systems with more than two dimensional components, such as plates, membranes, solids and shells, are complicated so that there is rarely an exact solution applicable to the differential equations (MCGUIRE; GALLAGHER \& ZIEMIEAN, 2000). The approach to such structures can only be made by numerical methods, usually based on the Newton-Raphson technique.

The present paper aims to present concepts and terminologies relevant to the stability theory and a numerical-computational method to analyze the stability of nonlinear systems with one and two degrees of freedom, without loss of the generality associated to more complex systems.

\section{CONCEPTS AND TERMINOLOGIES}

\section{The Stability Phenomenon}

The concept of stability can be easily visualized through a classical problem. Three

\footnotetext{
${ }^{1}$ Engenheiro civil e Mestre em Engenharia Civil; yargops@gmail.com

${ }^{2}$ Professor titular voluntário da Universidade Federal do Espírito Santo; walnorio@gmail.com
} 
cylindrical masses are resting on curved or straight surfaces, as shown in Figure 1.

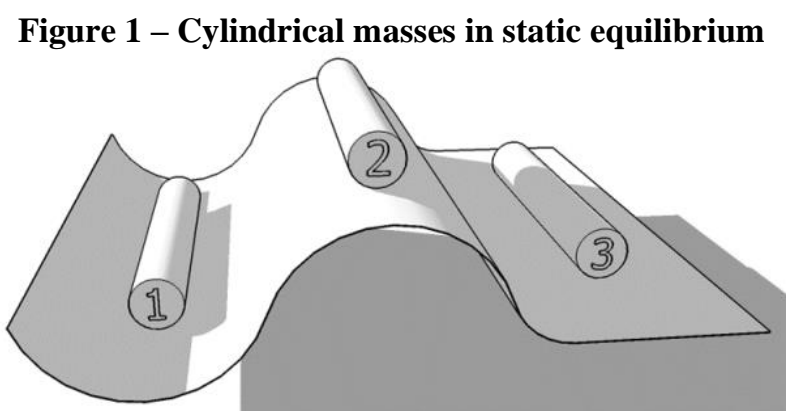

The three cylindrical masses rest on points without any inclination, which is because they can be considered in static equilibrium. However, the stability of each cylinder is different. If cylinder 1 undergoes a small disturbance, it returns to its initial equilibrium position. It is then said that its equilibrium position is stable. If cylinder 2 suffers a small disturbance, it moves away from the equilibrium position. It is then said that its equilibrium is unstable. Any perturbation applied to cylinder 3, on the other hand, will not change its stability condition: it will always be in equilibrium. It is then said that its equilibrium is neutral. A mechanical system can be evaluated according to three stability criteria: the static, dynamic, and energetic criterion. The energy criterion will be the one used herein and is stated below. Next, a numerical method applied to the physical problem of structural stability based on the Newton-Raphson strategy with incrementaliterative solution will be presented.

\section{Stationary potential energy principle (SPEP)}

For a structural system containing only conservative forces, in which the total potential energy is a continuous function of its displacement, among all the admissible configurations of the system displacements, the one which satisfies the equilibrium equations is the one that makes the total potential energy stationary, concerning a small allowable displacement variation. If the equilibrium configuration corresponds to a minimum of total potential energy, the equilibrium will be stable. If the equilibrium configuration corresponds to a maximum total potential energy, the equilibrium will be unstable (FERREIRA et al., 2017).

\section{Numerical Approach}

From the mechanical system, it is assumed that the static equations and the equilibrium system configuration are known. The method starts from the initial equilibrium configuration and searches for a next one, satisfying a certain error tolerance. The process is repeated until the desired point of the equilibrium path of the structure is established.

When analyzing the stability of a structural system, there is a set of control parameters (e.g., external loading) and, in order to determine the system global behavior and to identify the possible instability phenomena, one must study how the equilibrium configuration changes when each control parameter changes. This way, the equilibrium paths or trajectories (load $\times$ displacement curve) are obtained. Each point in the equilibrium path represents an admissible system equilibrium configuration. Usually, this path is smooth, i. e., it has a continuous tangent, with exceptions only in some special points. Such points are not easily captured by traditional numerical methods without a more sophisticated approach (OWEN \& HINTON, 1980).

Two phases can be identified to obtain the solution. The first one, called the predicted phase, when the strategy of load control is used, involves obtaining the incremental displacements from a given increase in load (SILVA et al., 2008). The second phase, called corrective, has the objective of correcting the internal generalized incremental forces obtained from the generalized displacement increments by the use of an iterative process. Such internal generalized forces are then compared with the external loading, obtaining the quantification of the existing lack of balance between internal and external generalized forces. The corrective process is repeated until, through a convergence criterion, the structure is in equilibrium. At the end of NewtonRaphson's corrective step, the load is increased 
and the next equilibrium configuration is obtained until the desired point of the equilibrium path of the structure is established
(MAXIMIANO, 2012). Figure 2 summarizes the method.

Figure 2 - Newton-Raphson procedure

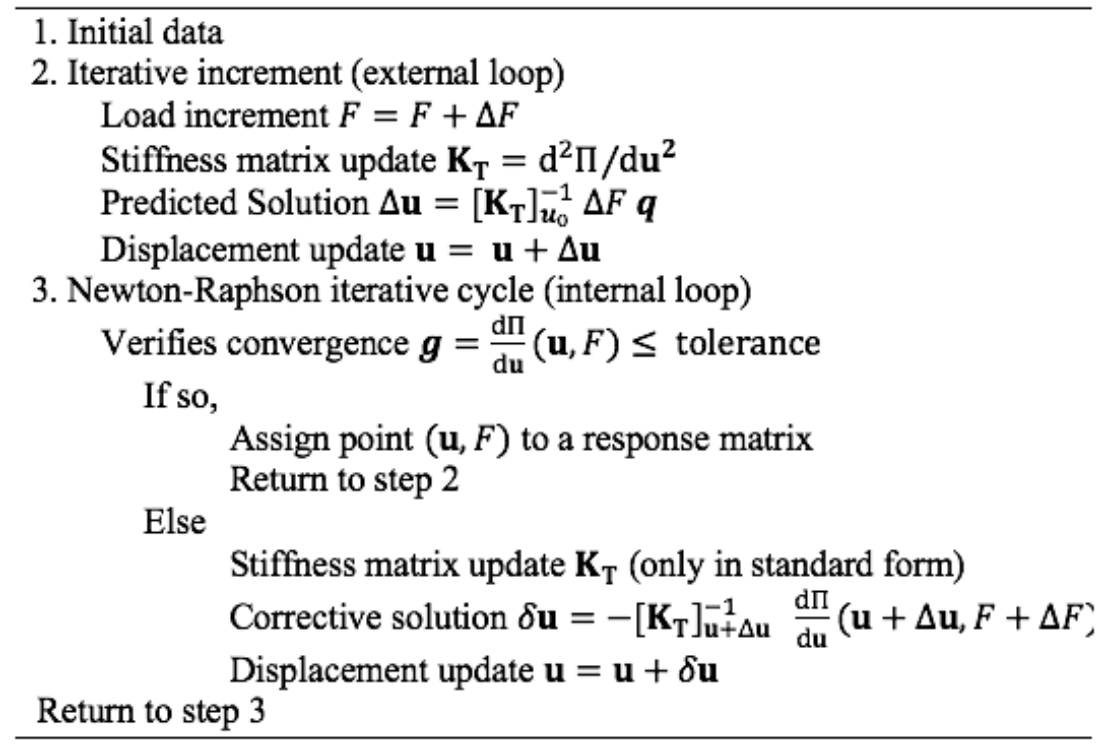

\section{APPLICATIONS}

\section{Mechanical system with one degree of freedom}

Figure 3 shows a system with a rigid weightless vertical bar of length $L$. Its lower end has a pin support. Its upper end is associated with a linear spring of stiffness $k$ and a vertical compression load $F$. The spring in turn is connected to a roller support. In (a) we have the system in its initial state and in (b) the disturbed state. The initial slope of the bar with respect to its vertical position $\varphi_{0}$ takes into account a geometric imperfection. The only system degree of freedom is the rotation $\varphi$ of the bar with respect to the vertical position.

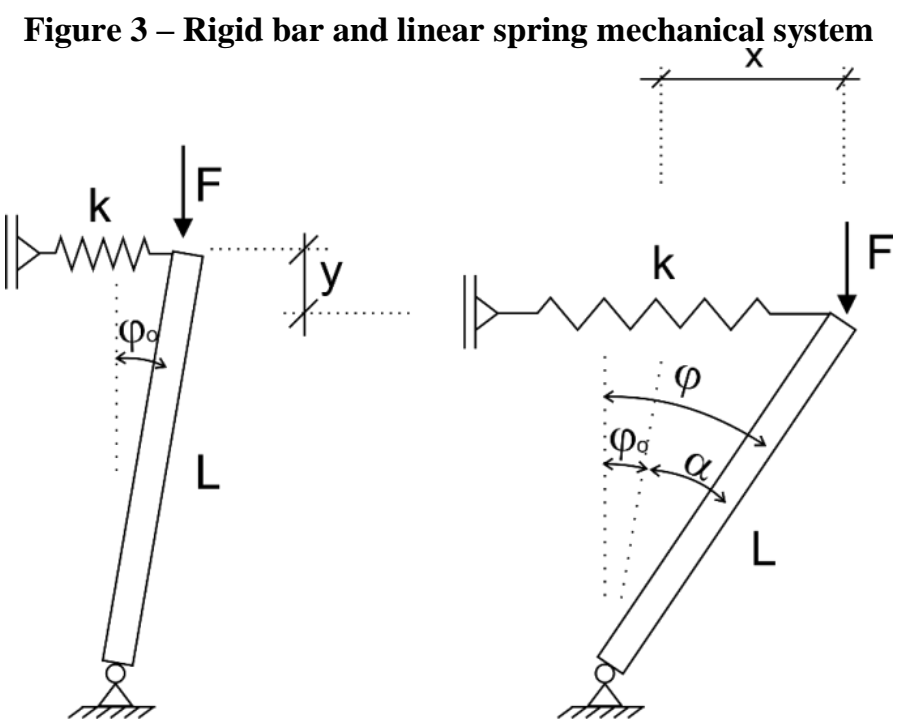


Figure 4 illustrates the solution of this system. Solid lines represent stable configurations and dashed lines unstable ones.

Figure 4 - a) Plot with the behavior of the system in Figure 3 b) variation of limit load with initial imperfection

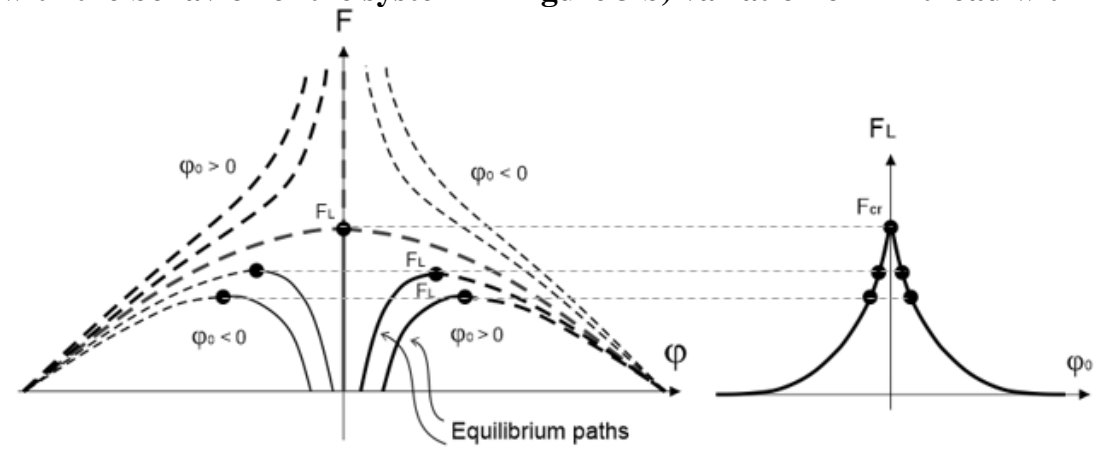

It is verified in this system that if one starts from $F=0$ the equilibrium path remains stable until a maximum value, represented by $F_{L}$, is reached; beyond that it becomes unstable. The point corresponding to that load is called the limit point (load limit point). This process of stability loss is called a dynamic jump. As the imperfection $\varphi_{0}$ of the system increases, the limit load becomes smaller and smaller (Figure 4b). The system without initial imperfection is known as the unstable symmetric bifurcation system (ALLEN et al, 1980). The same graphic (Figure 4) was obtained by Gonçalves and Batista (CARNEIRO et al., 1984), however, studying a complex problem of cylindrical shells stability.

Figure 5 presents this solution by the standard Newton-Raphson method with constant load control. Figure 6 shows the plot obtained by the computational program and its comparison with the analytical response.

Figure 5 - Newton-Raphson standard method for the unstable symmetric bifurcation system with initial geometric imperfection

1. Initial data

$$
\begin{aligned}
& n=10000 ; \text { tol }=0.1 ; \Delta F=0.01 ; k=30 ; L=6 \\
& F=0.1 ; \varphi=0.4 ; \varphi_{0}=5 \pi / 180
\end{aligned}
$$

2. Iterative increment (external loop)

Load increment $(F=F+\Delta F)$

Stiffness matrix update:

$\mathrm{K}_{T}=\mathrm{kL}^{2}\left(1+\sin \varphi \sin \varphi_{0}-2 \sin ^{2} \varphi\right)-\mathrm{FL} \cos \varphi$

Predicted displacement update $\left(\varphi=\varphi+\Delta F / \mathrm{K}_{\mathrm{T}}\right)$

3. Newton-Raphson iterative cycle (internal loop)

Calculates the unbalanced static equation:

$g=\mathrm{kL}^{2}\left(\sin \varphi-\sin \varphi_{0}\right) \cos \varphi-$ FL $\sin \varphi$

Verifies convergence $(g \leq$ tolerance $)$

If so,

Assign point $(\mathbf{u}, F)$ to a response matrix

Return to step 2

Else

Stiffness matrix update:

$\mathrm{K}_{T}=\mathrm{kL}^{2}\left(1+\sin \varphi \sin \varphi_{0}-2 \sin ^{2} \varphi\right)-\mathrm{FL} \cos \varphi$

Corrective displacement update $\left(\varphi=\varphi-g / \mathrm{K}_{\mathrm{T}}\right)$

Return to step 3 
Figure 6 - Comparison between analytical and numerical response of the system in Figure 3 with $k=30 \mathrm{kNm}$, $L=6 \mathrm{~m}$ and $\varphi_{-} 0=5^{\circ}$ by the standard Newton-Raphson method

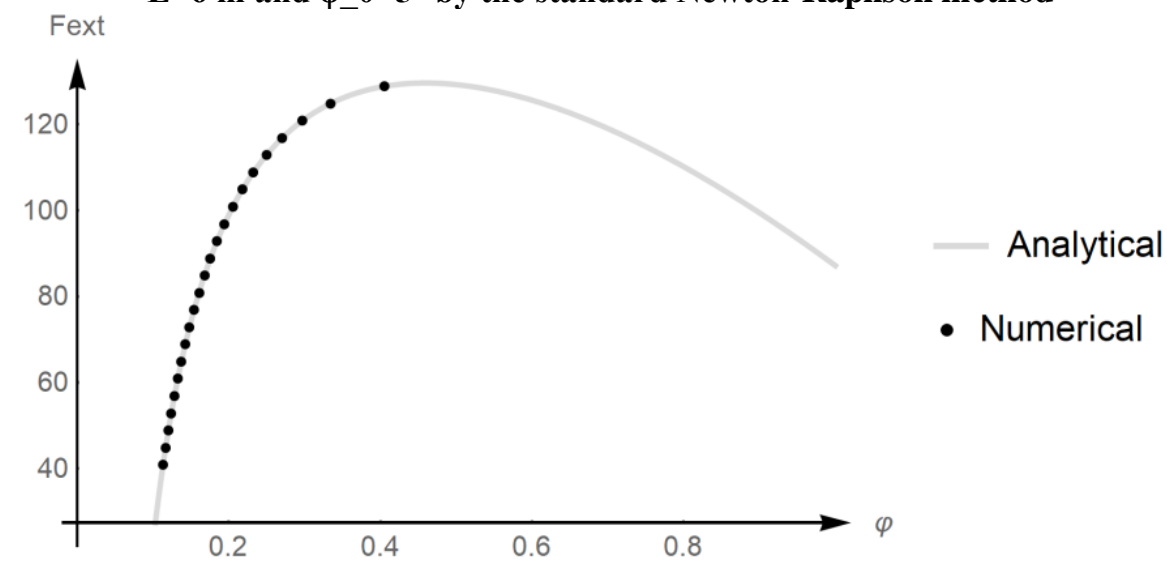

\section{Mechanical system with two degrees of freedom}

Consider now a mechanical system composed of three rigid weightless bars of length $L$, pinned to each other, and to two springs of linear stiffness and roller supports (except the pinned support at the bottom) as shown in Figure 7. The initial geometric imperfection can be introduced as an initial slope $\varphi_{0}$ on the bars directly attached to the supports. Another way of considering the initial imperfection, also introduced here, will be a load eccentricity. In Figure 7(a) the system is in the initial position. The configuration in any generic position, compatible with the system admissible displacements, can be seen in Figure 7(b), where are shown its two degree of freedom, $\varphi_{1}$ and $\varphi_{2}$.

The degrees of freedom of this system can be defined as the rotations of the bars attached to the supports with respect to the vertical position $\varphi_{1}$ and $\varphi_{2}$, since they can describe any configuration of the system.

$$
\Pi(\mathbf{u})=\mathrm{U}(\mathbf{u})+\mathrm{V}(\mathbf{u})
$$

where $\mathbf{u}$ is the degree of freedom vector of the system:

$$
\mathbf{u}=\left(\begin{array}{l}
\varphi_{1} \\
\varphi_{2}
\end{array}\right)
$$

$U(\mathbf{u})$ is the contribution of the potential energy relative to the internal spring energy:

$$
U(\mathbf{u})=\frac{k L^{2}}{2}\left[\left(\sin \varphi_{1}-\sin \varphi_{0}\right)^{2}+\left(\sin \varphi_{2}-\sin \varphi_{0}\right)^{2}\right]
$$

and $V(\mathbf{u})$ is the portion of the potential energy relative to the external load energy:
Figure 7 - Mechanical system with two degrees of position potential energy can be written as: 


$$
\begin{gathered}
\mathrm{V}(\boldsymbol{u})=-F L\left[1+2 \cos \varphi_{0}-\varepsilon\left(\varphi_{2}-\varphi_{0}\right)-\cos \varphi_{1}-\cos \varphi_{2}\right. \\
\left.-\sqrt{1-\left(\sin \varphi_{1}-\sin \varphi_{2}\right)^{2}}\right]
\end{gathered}
$$

Now the static system equations can be obtained:

where:

$$
\mathbf{g}(\mathbf{u})=\left(\begin{array}{c}
\frac{\partial \Pi(\mathbf{u})}{\partial \varphi_{1}} \\
\frac{\partial \Pi(\mathbf{u})}{\partial \varphi_{2}}
\end{array}\right)=\left(\begin{array}{l}
A(1,2) \\
A(2,1)
\end{array}\right)
$$

$$
A(i, j)=k L^{2} \cos \varphi_{i}\left(\sin \varphi_{i}-\sin \varphi_{0}\right)-F L\left[\sin \varphi_{i}+\frac{\left(\sin \varphi_{i}-\sin \varphi_{j}\right) \cos \varphi_{i}}{\sqrt{1-\left(\sin \varphi_{i}-\sin \varphi_{j}\right)^{2}}}-\varepsilon_{j}\right]
$$

where were adopted $\varepsilon_{1}=\varepsilon$ and $\varepsilon_{2}=0$, for simplicity.

By the SPEP it is known that the structure is in equilibrium when the system of static equations, obtained in Equation (9), is null. Since it is complicated to analytically solve the system of equations, the numerical approach will be used.

Note that, now, with the SPEP application, a matrix equation emerges. In the previous case, a system with one degree of freedom, the equation was scalar.
The data used are: $k=30 \mathrm{kNm} ; L=2 \mathrm{~m}$; $\varphi_{0}=0,05 \mathrm{rad}$. The process starts from the equilibrium point $\varphi_{1}=\varphi_{2}=0,9 \mathrm{rad}$ and $F=$ $36,3 k N$. Figure 8 presents this solution by the standard Newton-Raphson method with constant load control. Figure 9 shows the plot obtained by the numerical method and its comparison with the analytical response (obtained by solving Equation (9) with the initial data).

Figure 8 - Newton-Raphson standard method for the system with two degrees of freedom

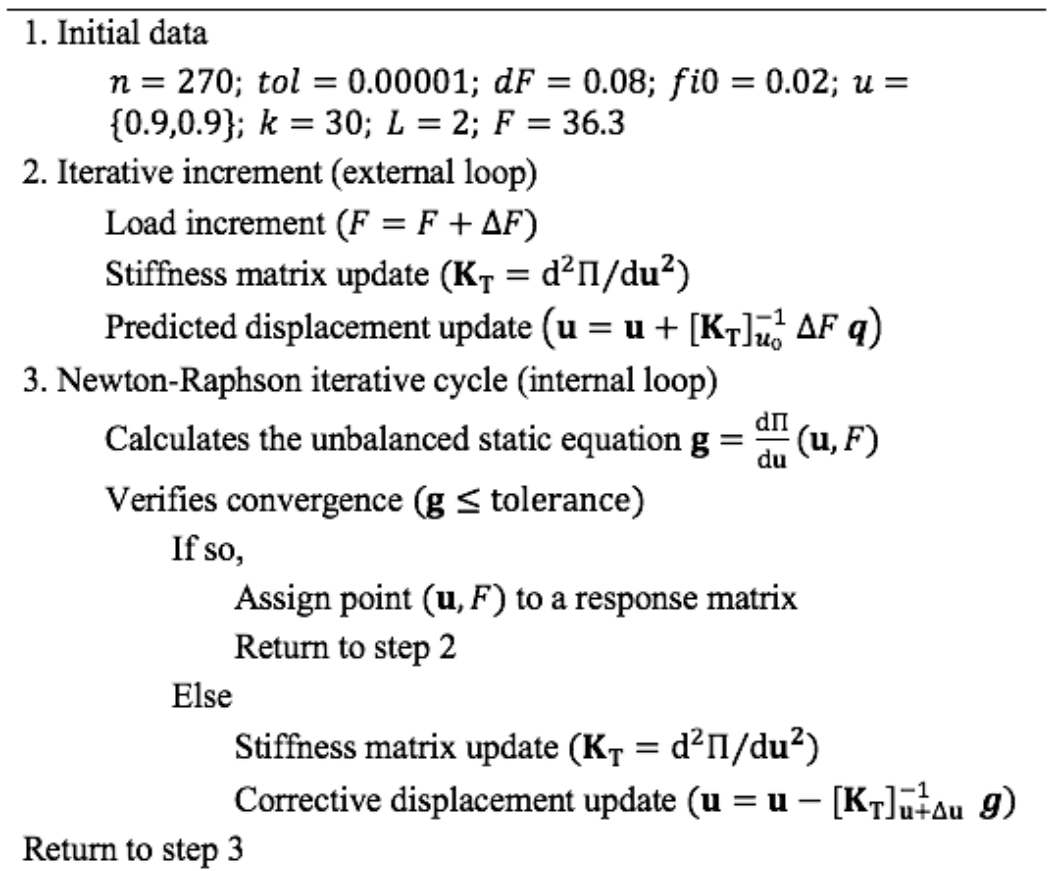


Figure 9 - Comparison between analytical and numerical response of the system in Figure 7 with $k=30 \mathrm{kNm}$, $L=6 \mathbf{m}$ and $\varphi_{-} 0=0,05$ rad by the standard Newton-Raphson method

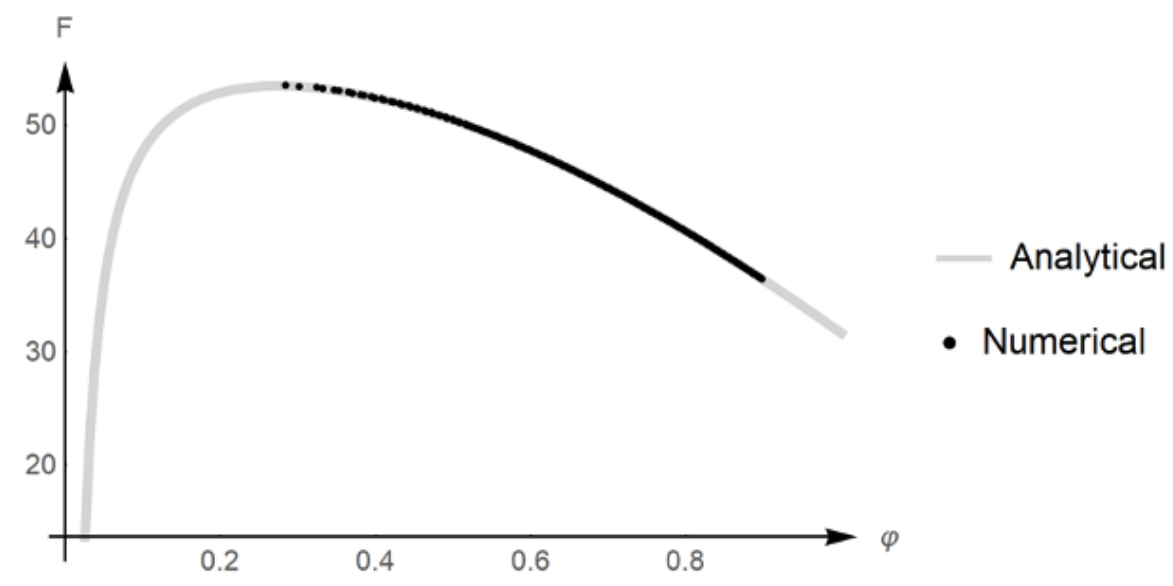

Ferreira et al. show that, when a small displacement theory was adopted, the matrix SPEP equation obtained by making $\mathbf{g}(\mathbf{u})=0$ using Eq. (9), with simplification, becomes an eigenvalue problem, with solutions: $\varphi_{1}=-\varphi_{2}$ with $F_{1}=k L / 3$; and $\varphi_{1}=\varphi_{2}$ with $F_{1}=k L$. (Figure 10), modes first and second, respectively.

Figure 10 - Mechanical system with two degrees of freedom (a) First buckling mode deformed shape (b) Second buckling mode deformed shape

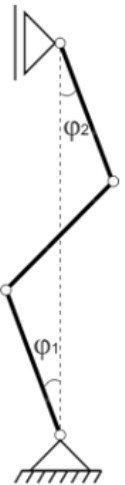

(a)

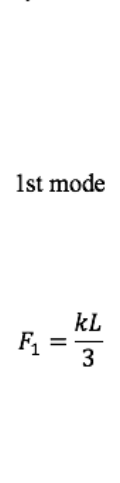

$F_{1}=\frac{k L}{3}$

CONCLUSION

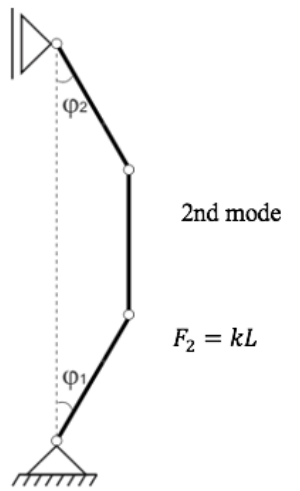

(b)
From the study of these systems and the creation of computational routines using the Newton-Raphson technique, it was possible to predict the geometric nonlinear behavior of these structures. These results serve as the basis for the study of more complex systems (with more degrees of freedom), with applications in civil or mechanical engineering. The article presented important aspects of structural stability. It concomitantly involved a stability theory with numerical implementation.

\section{Acknowledgements}

To Universidade Federal do Espírito Santo (UFES), to Conselho Nacional de Desenvolvimento Científico e Tecnológico (CNPq), the Brazilian National Council for the Scientific and Technological Development, and to Coordenação de Aperfeiçoamento de Pessoal de Nível Superior (CAPES), the Brazilian Coordination for Improvement of Higher Level Personnel (sponsoring agency), for the material conditions inherent to the elaboration of the research.

\section{REFERÊNCIAS}

the structural stability in an organized way in order to facilitate the understanding of the subject. In addition to presenting the basic concepts and terminologies pertinent to the theory of structural stability, it was possible to apply them in mechanical systems with single and two degrees of freedom composed of rigid weightless bars associated with linear springs.
ALLEN, H. G., \& Bulson, P. S. Background to Buckling, McGraw-Hill, 1980.

CARNEIRO, F. L. L. B. et al. Shell and Spacial Structures Engineering, Pentech Press Limited, 1984. 
FERREIRA, W. G. Design of elements with laminated and welded steel profiles, with numerical examples, Grafer, Vitória, 2004. (In portuguese).

FERREIRA, W. G., et al. Introducation to the Theory of Elastic Stability, $2^{\text {nd }}$ ed. Vitória: LBF, 2017. (In portuguese).

MAXIMIANO, D. P. An efficient technique to stabilize the orthogonal residue strategy in the nonlinear analysis of structures. Master's Thesis. Ouro Preto, 2012. (In portuguese)

MCGUIRE, W., GALLAGHER, R. H., \& ZIEMIEAN, R. D. Matrix Structural Analysis (2nd ed.). New York, EUA: John Wiley \& Sons, Inc, 2000.

OWEN, D. J., \& HINTON, E. Finite Elements in Plasticity: Theory and Practice. Pineridge Press Limited, 1980.

SILVA, A. R., SILVEIRA, R. A., NEVES, F. A., \& FERREIRA, W. G. Computational system for advanced analysis of Metal Structures, XXIX CILAMCE - IBERIAN LATIN AMERICAN CONGRESS ON COMPUTATIONAL METHODS IN ENGINEERING, 2008. (In portuguese).
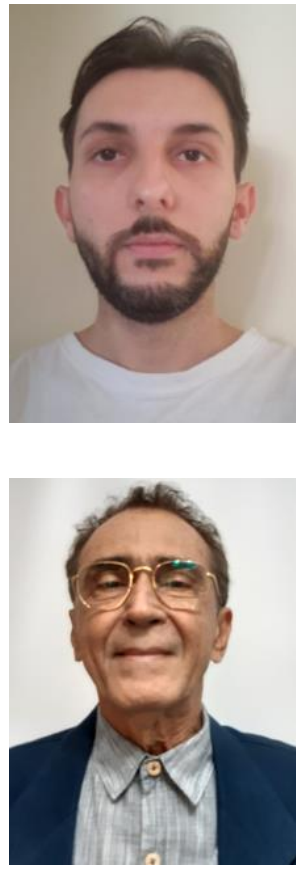

\section{DADOS BIOGRÁFICOS DOS AUTORES}

Yargo Pezzin Souza - Graduado em Engenharia Civil (UFES, 2015) e Mestre em Engenharia Civil (UFES, 2018). Áreas de atuação profissional e assuntos de interesse: projeto estrutural, estabilidade estrutural, métodos de integração temporal e métodos de redução de ordem do modelo de elementos finitos.
Walnório Graça Ferreira - Graduação em Engenharia Civil pela Universidade Federal do Ceará (1973), mestrado (1990) e doutorado (1998) em Engenharia Civil pela COPPE da Universidade Federal do Rio de Janeiro. Atualmente é professor titular voluntário da Universidade Federal do Espírito Santo. Aprovado em $1^{\circ}$ lugar em concurso público no Departamento de Engenharia Civil, Centro Tecnológico da Universidade Federal do Espírito Santo. Tem experiência na área de Engenharia Civil, com ênfase em Dinâmica Estrutural, Estruturas de Aço e Mistas e Engenharia de Incêndio (enfoque estrutural), atuando com entusiasmo no campo do ensino da engenharia nas áreas: estruturas de aço e mistas, concreto armado, resistência dos materiais, método dos elementos finitos, dentre outros. Publicou os seguintes livros 'Introdução à Teoria da Estabilidade Elástica: Conceitos, Implementações Computacionais e Aspectos Normativos' (3 edições e 2 reimpressões), 'Dimensionamento de Elementos de Perfis de Aço Laminados e Soldados' (3 edições), 'Aplicações Práticas de Problemas de Calor como Introdução ao Método dos Elementos Finitos', 'Dimensionamento de Estruturas de Aço e Mistas em Situação de Incêndio' (lançado na Europa (Portugal) e no Brasil) e 'Análise Dinâmica no Domínio da Frequência de Sistemas Estruturais'. 